\title{
Influence of Histamine H1 Receptor Antagonists on Thioredoxin Production In vitro and In vivo
}

\author{
Tomomi Mizuyoshi $^{1}$, Masayo Asano ${ }^{1}$, Atsuko Furuta ${ }^{1}$, Kazuhito Asano ${ }^{2^{\star}}$ and Hitome Kobayashi ${ }^{1}$ \\ ${ }^{1}$ Department of Otolaryngology, School of Medicine, Showa University, Shinagawa-ku, Tokyo, Japan \\ ${ }^{2}$ Division of Physiology, School of Nursing and Rehabilitation Sciences, Showa University, Midori-ku, Yokohama, Japan
}

"Corresponding author: Kazuhito Asano, Division of Physiology, School of Nursing and Rehabilitation Sciences, Showa University, 1865 Touka-Ichiba, Midori-ku, Yokohama 226-8555, Japan, Tel: +81 45985 6538; Fax: +81 45985 7583; E-mail: asanok@med.showa-u.ac.jp

Received date: May 08, 2017; Accepted date: May 16, 2017; Published date: May 24, 2017

Copyright: ( 2017 Mizuyoshi T, et al. This is an open-access article distributed under the terms of the Creative Commons Attribution License, which permits unrestricted use, distribution, and reproduction in any medium, provided the original author and source are credited.

\begin{abstract}
Background: Thioredoxin (TRX), a 12-kDa oxidoreductase enzyme, is well known to be a redox-active protein that regulates reactive oxidative metabolism. TRX is also accepted to be a protein with anti-inflammatory effects and reported to attenuate the development of allergic airway inflammatory diseases such as allergic rhinitis (AR) and asthma. Although histamine $\mathrm{H} 1$ receptor antagonists are frequently used for the treatment of AR, the influence of the agents on TRX production is not well understood. In the present study, we examined the influence of fexofenadine (FEX), cetirizine (CT), and levocetirizine (LCT), which are classified into histamine H1 receptor antagonists, on TRX production in vitro and in vivo.
\end{abstract}

Methods: Macrophages derived from THP-1 cells $\left(1 \times 10^{5}\right.$ cells $\left./ \mathrm{ml}\right)$ were cultured with $50 \mu \mathrm{M} \mathrm{H}_{2} \mathrm{O}_{2}$ in combination with/without the agents for $24 \mathrm{~h}$. Nasal secretions were obtained from patients with Japanese cedar pollen-sensitized rhinitis, who were treated with FEX or LCT for four weeks during pollen season. TRX contents in both culture supernatants and nasal secretions were examined by ELISA.

Results: Addition of FEX, CT and LCT into macrophage cultures increased TRX levels in supernatants. The minimum concentration of the agents that caused significant increase was $0.3 \mu \mathrm{M}$ for FEX, $0.4 \mu \mathrm{M}$ for CT and LCT. Treatment of patients with FEX and LCT also caused increase in TRX levels in nasal secretions along with attenuation of clinical symptoms.

Conclusion: Histamine $\mathrm{H} 1$ receptor antagonists may increase the ability of macrophages to produce TRX, and results in favorable modification of clinical conditions of AR.

Keywords: Macrophages; Thioredoxin; Fexofenadine; Levocetirizine; Allergic rhinitis; Increase; In vivo; In vitro

\section{Introduction}

Allergic rhinitis (AR) is accepted to be a type I hypersensitivity response to specific allergen(s) in nasal mucosa. On re-exposure to allergen(s) in sensitized individuals with $\mathrm{AR}$, cross-linking of $\operatorname{IgE}$ bounded to receptors on mast cell surface occurs and results in mast cell degranulation, releasing several types of chemical mediators such as histamine, leukotrienes and prostaglandins, which cause the development of clinical symptoms of AR such as sneezing, itching and nasal congestions $[1,2]$. In addition to mast cell degranulation, inhalation of allergens also causes the activation of epithelial cells and fibroblast in nasal mucosa [1,3]. These cellular events induce the tissue recruitment and migration of eosinophils into the nasal mucosa from blood vessels [1,2]. Activation of eosinophils causes the release of granule contents such as major basic protein, eosinophil cationic protein and eosinophil peroxidase that are responsible for tissue damages and remodeling after mucosal injury, leading to persistence of inflammatory responses in nasal mucosa [1-3]. In addition to granule contents, mast cells and eosinophils also secret free radicals, especially nitric oxide (NO) [4-6], which causes oxidative stress responses in inflammatory tissues through lipid peroxidation on the outer cell membrane, nuclear membrane and DNA damage $[7,8]$. Under normal physiological conditions, there is a wide variety of antioxidants, including superoxide dismutase and catalase, and prevent the oxidative stress responses [7]. In these antioxidants, thioredoxin (TRX) has attracted attention as a $12-\mathrm{kDa}$ ubiquitous protein, which shows antioxidative activity. TRX, which was originally identified as an electron donor to peroxidases and ribonucleotide reductase, is an oxidoreductase enzymes containing a dithiol-disulfide active site and operates as a scavenger of reactive oxygen species (ROS) and an inhibitor of intracellular ROS generation in many oxidative stress diseases such as diabetes, rheumatoid arthritis, cancer and asthma $[9,10]$. TRX is also reported to exert immunomodulatory effects. Treatment of asthmatic model mouse with TRX could suppress the development of airway hyper responsiveness induced by aerosolized acetylcholine $[11,12]$. It is also reported that administration of exogenous TRX prevents airway remodeling with intense infiltration of both eosinophils and macrophages through the suppression of Th2 cytokine (e.g. IL-4 and IL-5) production induced by inhalation of specific allergen $[11,12]$. Furthermore, TRX is reported to inhibit the production of regulated on activation, normal $\mathrm{T}$ cell expressed, and secreted (RANTES)- and eotaxin-induced migration of eosinophils, leading to attenuation of eosinophilic inflammatory responses in airways [13]. Although these reports strongly suggest that TRX plays a crucial role in the development of allergic diseases and will be a good 
target in the treatment of airway eosinophilic inflammatory disease, the influence of histamine $\mathrm{H} 1$ receptor antagonists, which are frequently used for the treatment of airway allergic diseases with remarkable success, is not well defined. In the present study, therefore, we examined the influence of histamine $\mathrm{H} 1$ receptor antagonists on TRX production in vitro and in vivo.

\section{Materials and Methods}

\section{Agents}

The histamine $\mathrm{H} 1$ receptor antagonists used in this study were chlorpheniramine $(\mathrm{CH})$, fexofenadine (FEX), cetirizine $(\mathrm{CT})$ and levocetirizine (LCT). These agents were synthetized in Toronto Research Chem., Inc. (North York, ON, Canada) and preservative free pure powders. These agents were dissolved in RPMI-1640 medium supplemented with $10 \%$ fetal bovine serum (RPMI-FCS), sterilized by passing through $0.2 \mu \mathrm{m}$ pore size filters and stored at $4^{\circ} \mathrm{C}$ until used. Phorbol 12-myristate 13-acetate (PMA) was purchased from SIGMA Chemicals Co., Ltd. (St. Louis, MO., USA). This was also dissolved in RPMI-FCS at a concentration of $200 \mathrm{nM}$, sterilized similar manner and stored at $4^{\circ} \mathrm{C}$ until used.

\section{Subjects and treatment}

The subjects were 32 male patients with Japanese cedar pollensensitized rhinitis. The subjects (15 patients) treated with FEX were recruited from Otolaryngology Outpatient Clinic of Showa University Fujigaoka Hospital (Yokohama, Japan) and the remaining subjects (17 patients) treated with LCT were recruited from Otolaryngology Outpatient Clinic of SASAKI hospital (Yokohama, Japan). All subjects were received a written informed consent approved by the Ethics Committee of Showa University. Pollinosis was diagnosed by otorhinolaryngologists in accordance with the established criteria on the basis of patient history and rhinoscopic examination. To confirm the diagnosis and demonstrate allergen-caused pollinosis, skin prick testing (mean wheal diameter at least $4 \mathrm{~mm}$ greater than negative control) and a nasal provocation test were performed with commercial crude extracts used for in vitro and in vivo (Torii Pharmaceutical Co., Ltd., Tokyo, Japan). The number of eosinophils in nasal secretions obtained after the provocation test was also examined using smears stained with Wright-Giemsa solution. We also recruited 5 male healthy subjects from the member of SASAKI Hospital (Yokohama, Japan) under a written informed consent, which was also approved by the Ethics Committee of Showa University. The characteristics of the subjects used in this study are shown in Table 1. Pollinosis patients were orally treated with either $60 \mathrm{mg}$ FEX (Sanofi Aventis, Tokyo, Japan) twice a day or $5 \mathrm{mg}$ LCT (Glaxo Smith Kline, Tokyo, Japan) once a day for 4 weeks during Japanese cedar pollen season (January 2016 to April 2016).

\begin{tabular}{|c|c|c|c|}
\hline & \multirow[t]{2}{*}{ Controls } & \multicolumn{2}{|c|}{ Patients treated with } \\
\hline & & FEX & LCT \\
\hline Number of subjects & 5 & 15 & 17 \\
\hline Age, years (range) & $42-61$ & $32-69$ & $25-66$ \\
\hline Sex & male & male & male \\
\hline Disease severity & nonallergic & mild & mild \\
\hline Medication & none & none & none \\
\hline Serum IgE (U/ml) & $40.6 \pm 8.7$ & $151.6 \pm 14.7$ & $149.6 \pm 12.4$ \\
\hline \multicolumn{4}{|l|}{ IgE RAST score } \\
\hline $\mathrm{Cj}$ & 0 & $53.8 \pm 10.2$ & $55.8 \pm 12.2$ \\
\hline $\mathrm{Aa}$ & 0 & 0 & 0 \\
\hline Ap & 0 & 0 & 0 \\
\hline $\mathrm{Dg}$ & 0 & 0 & 0 \\
\hline Df & 0 & 0 & 0 \\
\hline Af & 0 & 0 & 0 \\
\hline $\mathrm{Cd}$ & 0 & 0 & 0 \\
\hline $\mathrm{Dd}$ & 0 & 0 & 0 \\
\hline Blood eosinophil count, \% & $3.2 \pm 0.6$ & $16.2 \pm 0.8$ & $16.5 \pm 1.8$ \\
\hline Skin prick test & - & $+++^{a}$ & $+++^{a}$ \\
\hline
\end{tabular}




\begin{tabular}{|l|l|l|l|}
\hline Symptoms & - & $+++^{\mathrm{b}}$ & $>32$ \\
\hline $\begin{array}{l}\text { Smear cytology } \\
\text { (eosinophils, \%) }\end{array}$ & $<1$ & $>31$ \\
\hline $\begin{array}{l}\text { Cj: Cryptomeria japonica; Aa: Ambrosia artemisiifolia; Ap: Artemisia princeps; Dg: Dactylis giomerata; Df: Dermatophagoides farina; Af: Aspergillus fumigatus; Cd: cat } \\
\text { dander; Dd: dog dander. } \\
\text { aWheal reaction > 13mm and flare reaction > 30mm against C. japonica alone. bositive for sneezing/ itch, watery rhinorrhea and nasal blockage against C. japonica } \\
\text { alone. FEX: fexofenadine; LCT: levocetirizine. }\end{array}$
\end{tabular}

Table 1: Characteristics of subjects used for treatment.

\section{Recovery of nasal secretions}

Nasal secretions were obtained as previously described [14]. Briefly, a filter strip $(7 \times 30 \mathrm{~mm}$; Whatman No. 42$)$ was placed on the anterior portion of the inferior turbinates of the nose and left for $5 \mathrm{~min}$. To prepare the extract of nasal secretions, filter papers were cut into small pieces, suspended in PBS and rocking $12 \mathrm{~h}$ at $4^{\circ} \mathrm{C}$ and stored at $-80^{\circ} \mathrm{C}$ until used.

\section{Nasal symptom scores}

Nasal discharge and congestion were scored from 0 to $3(0=$ no, $1=$ mild, $2=$ moderate, $3=$ severe symptoms). The number of sneezes during one $h$ were counted and transformed into a score $(0=0$ sneezes, $1=1-4$ sneezes, $2=5-9$ sneezes, and $3=10$ or more sneezes). A total symptom score was calculated by adding these three scores.

\section{Cell culture}

Human monocytic leukemia cell line, THP-1 cell (ATCC No. TIB-202) at a concentration of $5 \times 10^{5}$ cells were stimulated with 100 nM PMA for $48 \mathrm{~h}$ for differentiation into macrophages [15]. After removing non-adherent cells by gentle washing with RPMI-FCS, the remaining cells, macrophages, were treated with $0.05 \%$ trypsin, washed 2 times with RPMI-FCS and used as a target cell for examining TRX production in vitro. In the case of examining the influence of $\mathrm{H}_{2} \mathrm{O}_{2}$ stimulation on TRX production, $1 \times 10^{5}$ cells were stimulated with various concentrations of $\mathrm{H}_{2} \mathrm{O}_{2}$ for 12 to $48 \mathrm{~h}$. Culture supernatants were obtained and stored at $-40^{\circ} \mathrm{C}$ until used. In the experiments examining the influence of $\mathrm{CH}, \mathrm{FEX}, \mathrm{CT}$ and LCT on TRX production, $1 \times 10^{5}$ cells were stimulated with $50 \mu \mathrm{M} \mathrm{H}_{2} \mathrm{O}_{2}$ in combination with/ without the agents for $24 \mathrm{~h}$. Culture supernatants were obtained and stored at $-40^{\circ} \mathrm{C}$ until used. In all experiments, treatment of cells with the agents was started $2 \mathrm{~h}$ before $\mathrm{H}_{2} \mathrm{O}_{2}$ stimulation.

\section{Assay for TRX}

TRX levels in culture supernatants were examined by human TRX ELISA test kits (Bio Vendor Lab. Med. Inc., Brno, Czech Republic) according to the manufacturer's recommendations, and the results were expressed as the mean $\mathrm{ng} / \mathrm{ml} \pm \mathrm{SE}$. TRX levels in nasal secretions was also measured by human TRX ELISA test kits (Bio Vendor Lab. Med. Inc.) in a similar manner. Simultaneously, IgA contents in nasal secretions were measured by human IgA ELISA test kits (Bethyl Laboratories, Inc., Montogomery, TX, USA) and TRX levels in the secretions were expressed as the mean $\mathrm{ng} / \mathrm{ng} \operatorname{IgA} \pm \mathrm{SE}$. The minimum detectable levels of TRX ELISA test kit was $2.13 \mathrm{ng} / \mathrm{ml}$.

\section{Assay for oxidative stress}

Oxidative stress responses in nasal cavity was assessed by measuring hydrogen peroxide levels in nasal secretions using d-ROM tests (DIACRON, Via Zircone, Italy) according to the manufacturer's recommendations. The results were expressed as Carratelli Units $(\mathrm{CARR} U) \pm \mathrm{SE}$.

\section{Statistical analysis}

Statistical significance between control and experimental groups was examined by ANOVA followed by Dunette's multiple comparison tests (SPSS Inc., Chicago, IL, USA). Paired t-test was used to examine the statistical significance between before and after treatment with either FEX or LCT. A p value $<0.05$ was accepted as statistically significant.

\section{Results}

\section{Effects of $\mathrm{H}_{2} \mathrm{O}_{2}$ stimulation on TRX production from macrophages in vitro}

The first experiments were carried out to examine whether $\mathrm{H}_{2} \mathrm{O}_{2}$ stimulation could increase the ability of macrophages to produce TRX. We firstly examined the optimal concentration of $\mathrm{H}_{2} \mathrm{O}_{2}$ to produce TRX from macrophages. Cells $\left(1 \times 10^{5}\right.$ cells $\left./ \mathrm{ml}\right)$ were stimulated with different concentrations of $\mathrm{H}_{2} \mathrm{O}_{2}$ for $24 \mathrm{~h}$ and TRX levels in culture supernatants were examined by ELISA. As shown in Figure 1a, $\mathrm{H}_{2} \mathrm{O}_{2}$ stimulation at more than $30 \mu \mathrm{M}$, but not $20 \mu \mathrm{M}$ increased TRX contents in culture supernatants and the maximum production of TRX was observed, when cells were cultured with $50 \mu \mathrm{M} \mathrm{H} \mathrm{H}_{2} \mathrm{O}_{2}$. We then examined the time course of TRX production from macrophages after $\mathrm{H}_{2} \mathrm{O}_{2}$ stimulation. Cells $\left(1 \times 10^{5}\right.$ cells/ml $)$ were stimulated with $50 \mu \mathrm{M}$ $\mathrm{H}_{2} \mathrm{O}_{2}$ for 12 to $48 \mathrm{~h}$ and TRX levels in culture supernatants were examined by ELISA. As shown in Figure 1b, TRX contents in culture supernatants peaked at $24 \mathrm{~h}$ and decline by $48 \mathrm{~h}$ after stimulation.

\section{Effects of histamine $\mathrm{H1}$ receptor antagonists on $\mathrm{H}_{2} \mathrm{O}_{2}$ - induced TRX production}

The thirds experiments were designed to examine the influence of histamine $\mathrm{H} 1$ receptor antagonists on TRX production from macrophages induced by $\mathrm{H}_{2} \mathrm{O}_{2}$ stimulation. Cells $\left(1 \times 10^{5}\right.$ cells $\left./ \mathrm{ml}\right)$ were cultured with $50 \mu \mathrm{M} \mathrm{H} \mathrm{H}_{2}$ in combination with/without $\mathrm{CH}$, FEX, CT and LCT for $24 \mathrm{~h}$, and TRX levels in culture supernatants were examined by ELISA. Addition of $\mathrm{CH}$ into cell cultures scarcely affected the ability of cells to produce TRX in response to $\mathrm{H}_{2} \mathrm{O}_{2}$ stimulation: TRX levels in experimental culture supernatants are similar (not significant) to that observed in appropriate control $\left(\mathrm{H}_{2} \mathrm{O}_{2}\right.$ 
alone; Figure 2a). However, addition of FEX at more than $0.3 \mu \mathrm{M}$ into cell cultures increased TRX levels in culture supernatants (Figure $2 \mathrm{~b}$ ). Furthermore, addition of CT and LCT at more than $0.4 \mu \mathrm{M}$ into cell cultures also caused increase in TRX levels in culture supernatants as in the case of FEX (Figures 3a and 3b).

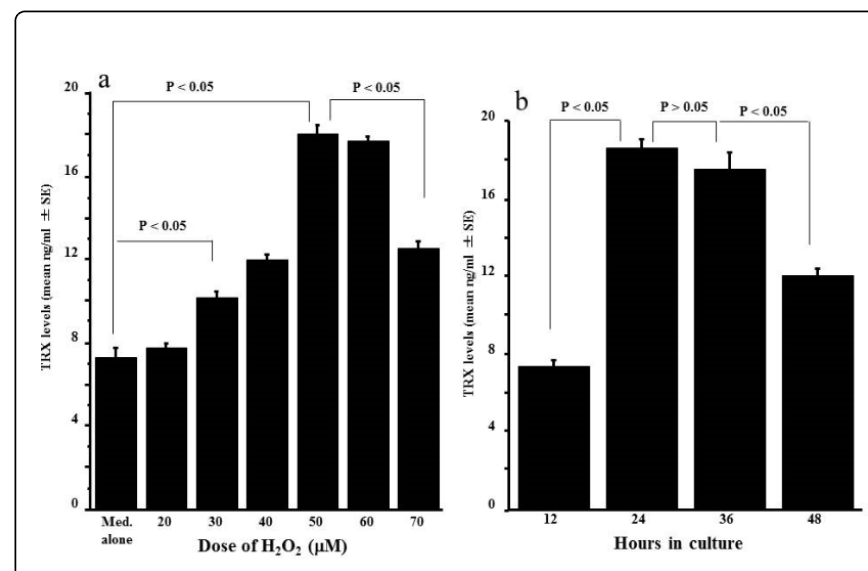

Figure 1: Influence of $\mathrm{H}_{2} \mathrm{O}_{2}$ stimulation on thioredoxin (TRX) production by macrophages derived from THP-1 cells in vitro. Macrophages $\left(1 \times 10^{5}\right.$ cells $\left./ \mathrm{ml}\right)$ were stimulated with various concentrations of $\mathrm{H}_{2} \mathrm{O}_{2}$ for $24 \mathrm{~h}$ (a) or with $50 \mu \mathrm{M} \mathrm{H} \mathrm{H}_{2} \mathrm{O}_{2}$ for indicated hours (b). The concentration of TRX in culture supernatants was then measured with ELISA. The results are expressed as the mean $\mathrm{ng} / \mathrm{ml} \pm \mathrm{SE}$ of triplicated cultures. The experiments were repeated twice with similar results.



Figure 2: Influence of chlorpheniramine $(\mathrm{CH})$ and fexofenadine (FEX) on thioredoxin (TRX) production by macrophages derived from THP-1 cells in vitro. Macrophages $\left(1 \times 10^{5}\right.$ cells $\left./ \mathrm{ml}\right)$ were stimulated with $50 \mu \mathrm{M} \mathrm{H} \mathrm{H}_{2} \mathrm{O}_{2}$ in combination with/without the agents for $24 \mathrm{~h}$, and TRX levels in culture supernatants were measured by ELISA. The results are expressed as the mean $\mathrm{ng} / \mathrm{ml} \pm$ SE of triplicated cultures. The experiments were repeated twice with similar results.

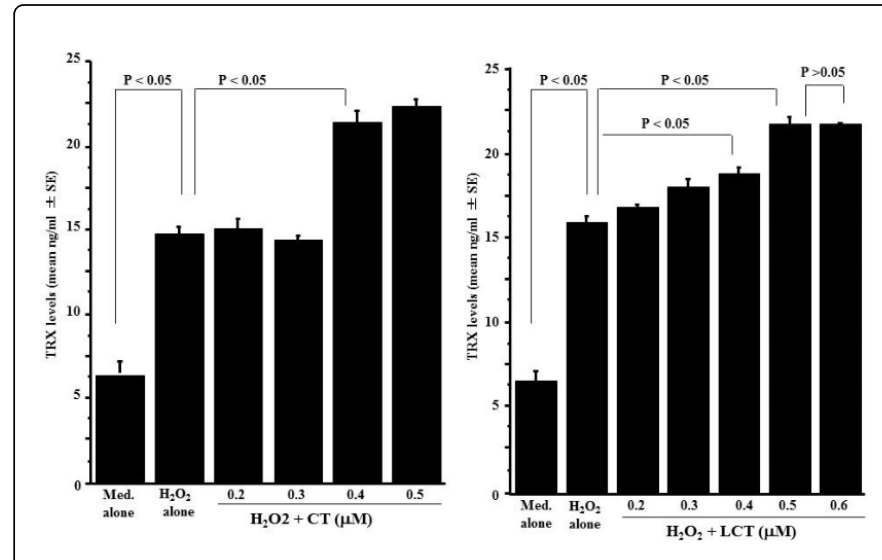

Figure 3: Influence of cetilizine (CT) and levocetirizine (LCT) on thioredoxin (TRX) production by macrophages derived from THP-1 cells in vitro. Macrophages $\left(1 \times 10^{5}\right.$ cells $\left./ \mathrm{ml}\right)$ were stimulated with $50 \mu \mathrm{M} \mathrm{H}_{2} \mathrm{O}_{2}$ in combination with/without the agents for $24 \mathrm{~h}$, and TRX levels in culture supernatants were measured by ELISA. The results are expressed as the mean $\mathrm{ng} / \mathrm{ml} \pm$ SE of triplicated cultures. The experiments were repeated twice with similar results.

\section{Influence of treatment of polinosis patients with FEX and} LCT on oxidative stress responses in nasal cavity

The fourth experiments were designed to examine whether oxidative stress responses were observed in pollinosis patients and administration of FEX and LCT into the patients could suppress oxidative stress responses. Pollinosis patients were treated with either $60 \mathrm{mg}$ FEX twice a day or $5 \mathrm{mg}$ LCT once a day for 4 weeks during Japanese cedar pollen season and hydrogen peroxide levels in nasal secretions were examined by d-ROM test. Treatment of the patients with FEX (Figure 4a) and LCT (Figure 4b) decreased significantly hydrogen peroxide levels in nasal secretions as compared with before treatment.

\section{Influence of treatment of pollinosis patients with FEX and LCT on TRX levels in nasal secretions}

The fifth experiments were undertaken to examine the influence of FEX and LCT on TRX appearance in nasal secretions. Pollinosis patients were treated with either $60 \mathrm{mg}$ FEX twice a day or $5 \mathrm{mg}$ LCT once a day for 4 weeks during Japanese cedar pollen season and TRX levels in nasal secretions were examined by ELISA. As shown in (Figures $5 \mathrm{a}$ and $5 \mathrm{~b}$ ), oral administration of FEX (a) and LCT (b) into the patients caused significant increase in TRX levels in nasal secretions as compared with before treatment. 
Page 5 of 7

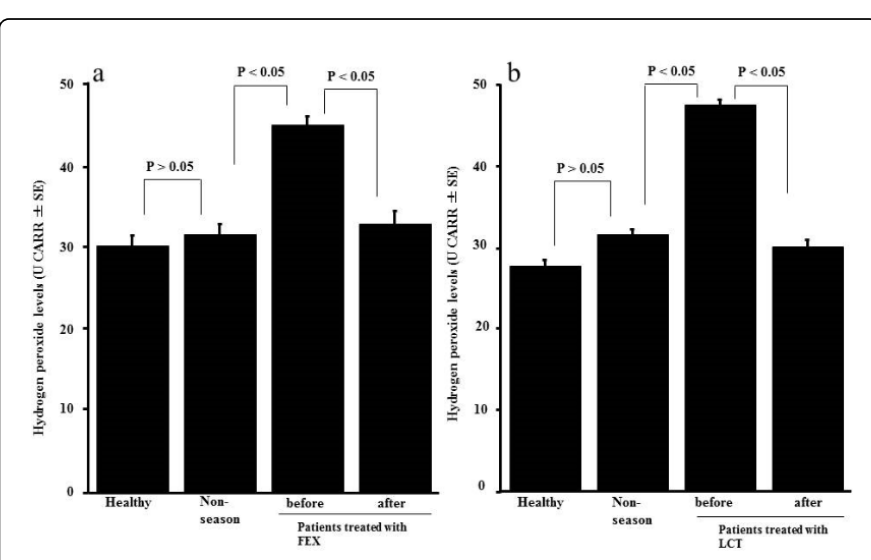

Figure 4: Influence of treatment of pollinosis patients with fexofenadine (FEX) and levocetirizine (LCT) on the appearance of hydrogen peroxide in nasal secretions. Pollinosis patients were orally treated with either $60 \mathrm{mg}$ FEX twice a day (a) or $5 \mathrm{mg}$ LCT once a day (b) for 4 weeks during Japanese cedar pollen season. Hydrogen peroxide levels in nasal secretions were measured with dROM tests and the results are expressed as the mean of Carratelli Units (CARR U) \pm SE of 15 patients for FEX and 17 patients for LCT.
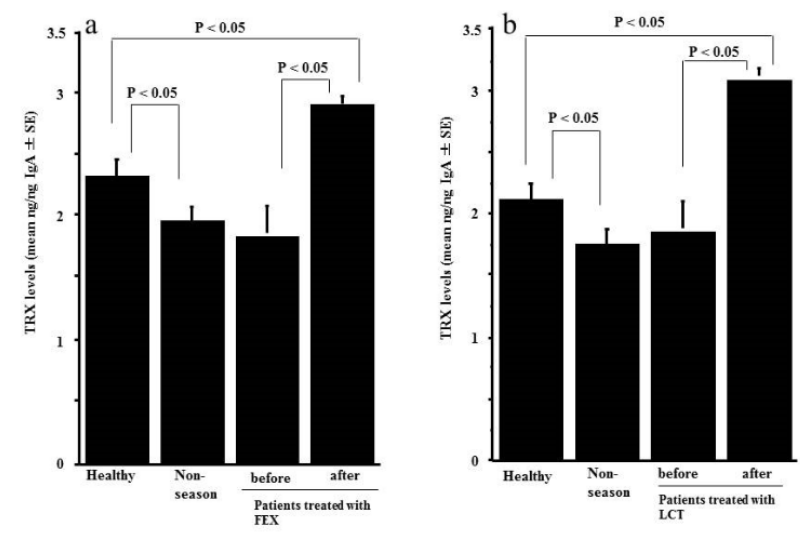

Figure 5: Influence of treatment of pollinosis patients with fexofenadine (FEX) and levocetirizine (LCT) on the appearance of thioredoxin (TRX) in nasal secretions. Pollinosis patients were orally treated with either $60 \mathrm{mg}$ FEX twice a day (a) or $5 \mathrm{mg}$ LCT once a day (b) for 4 weeks during Japanese cedar pollen season. TRX levels and IgA contents in nasal secretions were measured by ELISA, respectively and the results are expressed as the mean $\mathrm{ng} / \mathrm{ng}$ $\operatorname{IgA} \pm$ SE of 15 patients for FEX and 17 patients for LCT.

\section{Influence of treatment with FEX and LCT on clinical conditions of pollinosis patient}

The final experiments were designed to examine whether oral administration of either FEX or LCT into pollinosis patients could favorably modify the clinical conditions of the patients. As shown in Table 2, Clinical symptom scores decreased significantly after treatment.

\begin{tabular}{|l|l|l|l|l|}
\hline \multirow{2}{*}{ Symptoms } & \multicolumn{2}{l}{ Treatment with FEX } & \multicolumn{2}{l|}{ Treatment with LCT } \\
\cline { 2 - 5 } & Before & After $^{*}$ & Before & After $^{*}$ \\
\hline Sneezing & $2.5 \pm 0.4$ & $0.6 \pm 0.3$ & $2.4 \pm 0.5$ & $0.5 \pm 0.3$ \\
\hline Nasal discharge & $2.3 \pm 1.1$ & $1.5 \pm 0.9$ & $2.6 \pm 1.0$ & $1.3 \pm 0.7$ \\
\hline Congestion & $2.4 \pm 1.3$ & $0.9 \pm 0.3$ & $2.3 \pm 1.2$ & $1.0 \pm 0.2$ \\
\hline $\begin{array}{l}\text { FEX: fexofenadine; LCT: levocetirizine; }{ }^{*}: \text { P<0.005 as compared with before } \\
\text { treatment. }\end{array}$
\end{tabular}

Table 2: Changes in clinical symptom scores observed in pollinosis patients treated with histamine $\mathrm{H} 1$ receptor antagonists for 4 weeks.

\section{Discussion}

The data obtained from the in vitro experiments clearly showed that the second- (CT and FEX) and the third (LCT)-, but not the first $(\mathrm{CH})$-generation histamine $\mathrm{H} 1$ receptor antagonists enhance the ability of macrophages to produce TRX in response to the stimulation with oxidant species, $\mathrm{H}_{2} \mathrm{O}_{2}$, in vitro. The minimum concentration that caused significant increase in TRX levels in culture supernatants was $0.3 \mu \mathrm{M}$ for FEX, and $0.4 \mu \mathrm{M}$ for CT and LCT, which are similar to therapeutic blood levels [16].

$\mathrm{AR}$ is well known to be an inflammatory reaction of the nasal mucosa mediated by an IgE-associated response against specific allergen(s) [1,2]. It is also accepted that AR is characterized by a two phase allergic reaction: an initial sensitization phase where allergen exposure results in IgE production, and subsequent clinical disease after repeated allergen exposure $[1,2]$. The clinical allergic reaction is further subdivided into early- and late-phase responses. In early-phase response, cross-linking of IgE with an allergen results in rapid release of several types of mediators such as histamine, prostaglandin and leukotrienes, from mast cells and basophils. These responses occur within $5 \mathrm{~min}$ after allergen exposure, and responsible for development of some of the general symptoms associated with AR, including mucosal edema, watery rhinorrhea and sneezing $[1,2,17]$. On the other hand, the late-phase response, which occurred 4-6 hours after allergen exposure, is characterized by the recruitment and activation of inflammatory cells (e.g. eosinophils, macrophages and T cells) within nasal mucosa, resulting in increased symptoms usually associated with nasal congestion, tissue damages and remodeling through the secretion of major basic protein and eosinophilc cationic protein, among others $[1,2,17]$. In addition to these mediators, inflammatory cells, including mast cells, eosinophils and macrophages produce ROS, especially NO [4-6]. In low/moderate concentration of ROS are essential for maintaining normal physiological functions, but excess productions and/or decreased levels in antioxidant(s) lead to oxidative stresses $[7,18,19]$. TRX is well known to be one of the most important regulators of reduction/oxidation (redox) balance and to inhibit intracellular ROS generation [11-13,20], which causes tissue injury at the inflamed site during AR [21,22]. It is reported that TRX suppressed the CC chemokine-induced chemotaxis of eosinophils through inhibition of both activation of extracellular signal-regulated kinase $1 / 2$ and p38 mitogen-activated protein kinase pathways [22], which play an important role in eosinophil chemotaxis [23]. Treatment of mice with TRX prevents the establishment of airway inflammation and overproduction of macrophage inflammatory protein (MIP)-1, RANTES, IL-4 and IL-5, which are involved in the pathogenesis of allergic inflammation, in chronic antigen exposure mice $[11,12]$. 
Furthermore, it is also reported that airway remodeling and eosinophilic inflammation induced by chronic antigen exposure prevented in TRX transgenic mice that showed the constitutive overproduction of TRX [12]. Together with these reports, the in vitro experimental results may be interpreted that the second-and the third-, but not the first-, generation histamine $\mathrm{H} 1$ receptor antagonists increase TRX levels in nasal mucosa and results in favorable modification of clinical symptoms in AR. However, before drawing the conclusion that the enhancement of TRX production from inflammatory cells by histamine $\mathrm{H} 1$ receptor antagonists may account for the therapeutic mode of action of the agents on AR, it is necessary to examine the influence of the agents on TRX production in vivo. We, therefore, then examined the influence of the agents on TRX production in vivo using pollinosis patients treated with either FEX or LCT for four weeks during Japanese cedar pollen season. The data obtained in the second part of experiments clearly showed that nasal secretions obtained pollinosis patients before treatment contained much higher levels of hydrogen peroxide as compared with those from healthy control, and that oral administration of both FEX and LCT into the patients caused decrease in hydrogen peroxide levels in nasal secretions along with the increase in TRX levels in nasal secretions. It is also showed that treatment of pollinosis patients with either FEX or LCT favorably modify the clinical symptoms induced by Japanese cedar pollen inhalation, suggesting that enhancement of TRX production by histamine $\mathrm{H} 1$ receptor antagonists constitute, in part, of a therapeutic mode of action of the agents on AR.

Although the present results clearly show that histamine H1 receptor antagonists, especially FEX, CT and LCT enhance the ability of cells (e.g. macrophages) to produce TRX in response to the stimulation with either $\mathrm{H}_{2} \mathrm{O}_{2}$ or specific allergen(s) in vitro and in vivo, the precise mechanisms by which the agents could increase TRX production are not clear understood. Our previous reports showed that histamine $\mathrm{H} 1$ receptor antagonists, FEX and LCT, caused increase in the production of $\mathrm{CC} 10$, which is an important endogenous protein exerting anti-inflammatory effects, in spite of the suppression of its mRNA expression from nasal epithelial cells after TNF- $\alpha$ stimulation and that this is due, in part, to the up-regulation of translation of CC10 mRNA in ribosome [14,24]. From these experimental data, there is possibility that FEX and LCT increase translation of TRX mRNA and results in appearance of large amount of TRX in both culture supernatants and nasal secretions. Further experiments are required to clarify this point.

In conclusion, the present results may suggest that some of therapeutic mode of action of histamine $\mathrm{H} 1$ receptor antagonists, especially FEX and LCT, in AR depend on their ability to increase TRX production from macrophages and nasal cells such as epithelial cells induced by the stimulation with ROS and/or allergen(s).

\section{Disclosure Statement}

All authors declare that they have no competing interest.

\section{References}

1. Pawankar R, Mori S, Kimura S (2011) Overview on the pathomechanisms of allergic rhinitis. Asia Pac Allergy 1: 157-167.

2. Ramirez-Jimenez F, Pavon-Romero G, Juarez-Martinez LL, Teran LM (2012) Allergic rhinitis. J Allergy Ther S5: 006.

3. Broide DH (2010) Allergic rhinitis: Pathophysiology. Allergy Asthma Proc 31: 370-374.
4. Min A, Lee YA, Kim K, EI-Benna J, Shin MH, et al. (2014) Nox2-derived ROS-mediated surface translocation of BLT1 is essential for exocytosis in human eosinophils induced by LBT4. Int Arch Allergy Immunol 165: 40-51.

5. Suojalehto H, Vehmas T, Lindstrom I, Kennedy DW, Kilpelainen M, et al. (2014) Nasal nitric oxide is dependent on sinus obstruction in allergic rhinitis. Laryngoscope 124: E213-218.

6. Imoto Y, Yamada T, Tsukahara H, Kimura Y, Kato Y, et al. (2015) Nitrite/ nitrate in nasal lavage fluid reflects nasal symptoms after a single nasal allergen provocation in patients with seasonal allergic rhinitis. J Invest Allergol Clin Immunol 25: 382-384.

7. Sen S, Chakraborty R, Sridhar C, Reddy YSR, De B, et al. (2010) Free radicals, antioxidants, diseases and phytomedicines: Current status and future prospect. Int J Pharm Sci Rev Res 3: 91-100.

8. Nathan C, Cunningham-Bussel A (2013) Beyond oxidative stress: an immunologist's guide to reactive oxygen species. Nat Rev Immunol 13: 349-361.

9. Burke-Gaffney A, Callister MEJ, Nakamura H (2005) Thioredoxin: friend or foe in human disease. TREND Pharm Sci 26: 398-404.

10. Holmgren A, Lu J (2010) Thioredoxin and thioredoxin reductase: Current research with special reference to human disease. Biochem Biophys Res Commu 396: 120-124.

11. Ichiki H, Hoshino T, Kinoshita T, Imaoka H, Kato S, et al. (2005) Thioredoxin suppresses airway hyperresponsiveness and airway inflammation in asthma. Biochem Biophys Res Commu 334: 1141-1148.

12. Imaoka H, Hoshino T, Takei S, Sakazaki Y, Kinoshita T, et al. (2007) Effects of thioredoxin on established airway remodeling in a chronic antigen exposure asthma model. Biochem Biophys Res Commu 360: 525-530.

13. Ito W, Kobayashi N, Takeda M, Ueki S, Kayaba H, et al. (2011) Thioredoxin in allergic inflammation. Int Arch Allergy Immunol. 155: 142-146.

14. Nogaki T, Asano K, Furuta A, Kanai K, Suzaki I, et al. (2012) Enhancement of clara cell $10-\mathrm{kDa}$ protein (CC10) production from nasal epithelial cells by fexofenadine hydrochloride. Asian Pac J Allergy Immunol 30: 139-145.

15. Tanaka M, Kishimoto Y, Saita E, Suzuki-Sugihara N, Kamiya T, et al. (2016) Terminalia bellirica extract inhibits low-density lipoprotein oxidation and macrophage inflammatory response in vitro. Antioxidants 5: 20 .

16. Schoepke N, Church MK, Maurer M (2013) The inhibition of levocetirizine and fexofenadine of the histamine-induced wheal and flare response in healthy Caucasian and Japanese volunteers. Acta Derm Venereol 93: 286-293.

17. Rosenwasser LJ (2011) Understanding of the pathophysiology of allergic rhinitis. Immunol Allergy Clin N Am 31: 433-439.

18. Valko M, Izakovic M, Mazur M, Rhodes CJ, Telser J, et al. (2004) Role of oxygen radicals in DNA damage and cancer incidence. Mol Cell Biochem 266: 37-56.

19. Poli G, Leonardduzzi G, Biasi F, Chiarpotto E (2004) Oxidative stress and cell signaling. Curr Med Chem 11: 1163-1182.

20. Kondo N, Nakamura H, Masutani H, Yodoi J (2006) Redox regulation of human thioredoxin network. Antioxid Redox Signal 8: 1881-1890.

21. Barnes PJ (1990) Reactive oxygen species and airway inflammation. Free Radic Biol Med 9: 235-243.

22. Sannohe S, Adachi T, Hamada K, Honda K, Yamada Y, et al. (2003) Up regulated response to chemokines in oxidative metabolism of eosinophils in asthma and allergic rhinitis. Eur Respir J 21: 925-931.

23. Kobayashi N, Yamada Y, Ito W, Ueki S, Kayaba H, et al. (2009) Thioredoxin reduces C-C chemokine-induced chemotaxis of human eosinophils. Allergy 64: 1130-1135.

24. Suzuki T, Asano K, Furuta A, Kanai K, Hinohira Y, et al. (2014) Enhancement of CC10 production from human nasal epithelial cells by histamine $\mathrm{H} 1$ receptor antagonists, desloratadine and levocetirizine in vitro and in vivo. J Clin Immunol Immunother 1: 001. 